\title{
SOCIETAL APPLICATIONS IN FISHERIES AND AQUACULTURE USING REMOTELY-SENSED IMAGERY - THE SAFARI PROJECT
}

\author{
Marie-Hélène Forget $^{(1)}$, Trevor Platt ${ }^{(2)}$, Shubha Sathyendranath ${ }^{(3)}$ Venetia Stuart $^{(2)}$ \\ Lisa Delaney ${ }^{(2)}$ \\ (1) Dalhousie University, Oceanography Department, 1355 Oxford Street, Halifax \\ NS, B3H 4J1, Canada, Email: mforget@dal.ca \\ (2) Plymouth Marine Laboratory, Prospect Place, The Hoe, Plymouth, PL1 3DH, UK, \\ Email: tplatt@dal.ca; shubha@dal.ca; info@geosafari.org

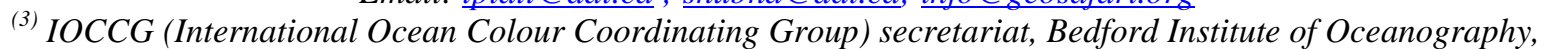 \\ 1 Challenger Drive, Dartmouth NS, B2Y 4A2, Canada, Email: vstuart@ioccg.org
}

\begin{abstract}
The principal objective of the SAFARI (Societal Applications in Fisheries and Aquaculture using Remotely-Sensed Imagery) initiative is to coordinate, at the international level, applications of remotelysensed Earth Observation data to the societal benefit areas of fisheries and aquaculture. Applications of remote sensing to fisheries include its use in i) fish stock assessment, where earth observation data is instrumental in the understanding of the effect of seasonal and inter-annual variability of the phytoplankton community to stock growth and recruitment, ii) in fisheries harvesting by identification, for example, of potential fishing zones, and iii) more generally in fisheries management, where the concept of the ecosystem-based approach is now universally accepted and introduced in the regional management of fisheries. Remotely-sensed Earth observation data are also useful in fisheries management for monitoring water quality and Harmful Algal Blooms (HAB) in coastal waters, helping with the protection of endangered species and creation of marine protected areas.
\end{abstract}

To achieve its main objective, the SAFARI initiative endeavours to reach all levels of participants engaged in global fisheries research and management, including policy makers, research scientists, government managers, and those involved in the fishing industries. SAFARI activities include organization of international workshops and symposia as a platform to discuss current research in Earth observation and fisheries management, information sessions aimed at the fisheries industry, government officials and resource managers, representation at policy meetings, and producing publications relevant to the activities. Researchers from more than 15 countries including India, Japan, Sri Lanka, France, UK, Spain, Italy, Canada, USA, Australia, New Caledonia, Peru, Argentina, Columbia and South Africa, are part of the SAFARI network, have attended workshops organized by SAFARI and contributed to a monograph on the topic to be published by the IOCCG (International Ocean-Colour Coordinating Group). Moreover, collaboration with other international networks, such as ChloroGIN (Chlorophyll Global Integrated Network) will facilitate the expansion of SAFARI worldwide. This community white paper, relevant to theme three of the conference, provides a portrait of the current and potential benefits of remotely-sensed data to society, and more specifically to management of fisheries and aquaculture at the global scale.

\section{INTRODUCTION}

Earth observation has a great deal of potential to benefit various activities covered generally under the heading of Fisheries and Aquaculture. In fact, many initiatives related to fisheries applications of remote sensing have already been initiated over the past decade. The SAFARI (Societal Applications in Fisheries and Aquaculture using Remotely-Sensed Imagery) initiative was launched in 2007 as the lead project of task number AG-06-02 of the Group on Earth Observation (GEO). The intergovernmental GEO are at the forefront of a global effort to build a Global Earth Observation System of Systems (GEOSS), which will build upon existing national, regional, and international systems to provide comprehensive, coordinated Earth observations. GEOSS will yield a broad range of societal benefits, such as the improvement of management and protection of terrestrial, coastal and marine ecosystems and supporting sustainable agriculture and aquaculture programs. The principal objective of SAFARI is to coordinate, at the international level, applications of remote sensing to the particular societal benefit areas of fisheries and aquaculture. To achieve this goal, SAFARI has created a network of interested parties involved in remote sensing and fisheries, at the international level.

Remote sensing of ocean colour provides our only window into the ocean ecosystem on synoptic scales. It is the sole method we have available to take a global view of the marine biosphere, and thus it can help us to learn how the marine ecosystem is responding to global warming and ocean acidification. Moreover, as an aid to fisheries and aquaculture management, remotely- 
sensed data can be used to monitor water quality in coastal habitats and detect the onset, expansion and fate of harmful algal blooms. Remote sensing can also be used to delineate optimal sites for marine protected areas or aquaculture farms. Finally, the international consensus to follow an ecosystem-based approach to fisheries management raises the imperative to design and implement a suite of ecological indicators with a view to detecting change in the ocean ecosystem, should it occur in response to perturbations, for example by climate change or by over-fishing. Such indicators would also be responsive to seasonal and inter-annual changes in the ecosystem, and thus be of use to fisheries research and management. Because of its high resolution in space and time, and low incremental cost, Earth observation by remote sensing will be of the utmost importance in this regard, and it is thus critical to ensure the continuity of the data stream (see the Ocean Colour Radiometry Virtual Constellation White Paper).

This community white paper is relevant to theme three of the OceanObs'09 conference, providing a portrait of the current and potential benefits of remotely-sensed data to society and, more specifically, to management of fisheries and aquaculture at the global scale.

The primary objective of SAFARI is to integrate the activities of experts in fisheries and Earth observation to accelerate the pace of assimilation of Earth observation into fisheries research and ecosystembased fisheries management on a world scale. SAFARI will also help to build capacity at the science level and the operational level, and facilitate the application of rapidly-evolving satellite technology to fisheries management questions on a global scale.

To achieve these objectives, all levels of participants in the global fisheries management, namely ministeriallevel decision makers, research scientists, government managers, and those involved in fisheries industries, have to be informed of the advantages in using Earthobservation data for management and exploitation of fisheries resources. SAFARI has already conducted a series of activities for promoting remote-sensing applications in fisheries and aquaculture. Following is a description of past events within the SAFARI initiative as well as a number of recommendations for future Earth observation strategies.

\section{APPLICATIONS OF REMOTE SENSING TO FISHERIES}

2.1 Ecosystem variability and climate change as measured by remote sensing and applications to fish-stock assessment

Variation in the timing and location of phytoplankton blooms has profound effects on the number of larval fish and invertebrates that survive and are recruited each year, and ultimately on the structure and dynamics of marine ecosystems. The spring phytoplankton bloom is the only source of food at the initial stages of the cycle of many fish and invertebrate larvae. The degree of spatial and temporal overlap of the spring phytoplankton bloom with the timing and spatial distribution of the spawning of eggs onto the surface waters has a strong influence on larval fish survival (Fig. 1). The larvae of many commercially-important species of fish and shellfish develop in the pelagic zone of the water column for 1-2 months before descending to the sea floor. Larvae of fish and invertebrates have sufficient yolk stores to survive for only a small fraction of the total time spent during development in the surface waters. Larvae starve and die unless they are spawned into, or transported into, a patch of phytoplankton and zooplankton that is sufficiently large and productive enough to sustain their food requirements for development. The variable pattern of recruitment of fish and invertebrates to juvenile stages is modulated by seasonal and inter-annual variation of phytoplankton and thus environmental variability affects recruitment of new individuals to exploited stocks and the productivity and biomass of higher trophic levels. Remotely-sensed images provide data at the resolution in time and space necessary to elucidate the linkages between climate-driven changes or natural variability in the marine environment and the dynamics of fish and ecosystem productivity.

\subsection{Remote Sensing Applications to Fisheries Management}

There is a general consensus that the sustainable management of the fisheries cannot be achieved by focusing only on the species of interest, but that it requires extending the health and conservation effort to the entire ecosystem, a concept commonly referred to as the ecosystem-based management of the marine resources. However, field measurements of biological and physical processes in the ocean are expensive and time consuming and provide only sparse temporal and spatial coverage. On the other hand, the continuity, global coverage and high temporal and spatial resolution of satellite observations can provide costeffective measurements of ecological indicators that can be applied serially and operationally in ecosystembased management. Remote sensing of ocean colour allows the understanding of the seasonal and interannual variability in the dynamics of phytoplankton, which is at the basis of the food web. Using ecological indicators determined by Earth observation will help characterise ecosystem changes following perturbations by natural or man-made causes. 


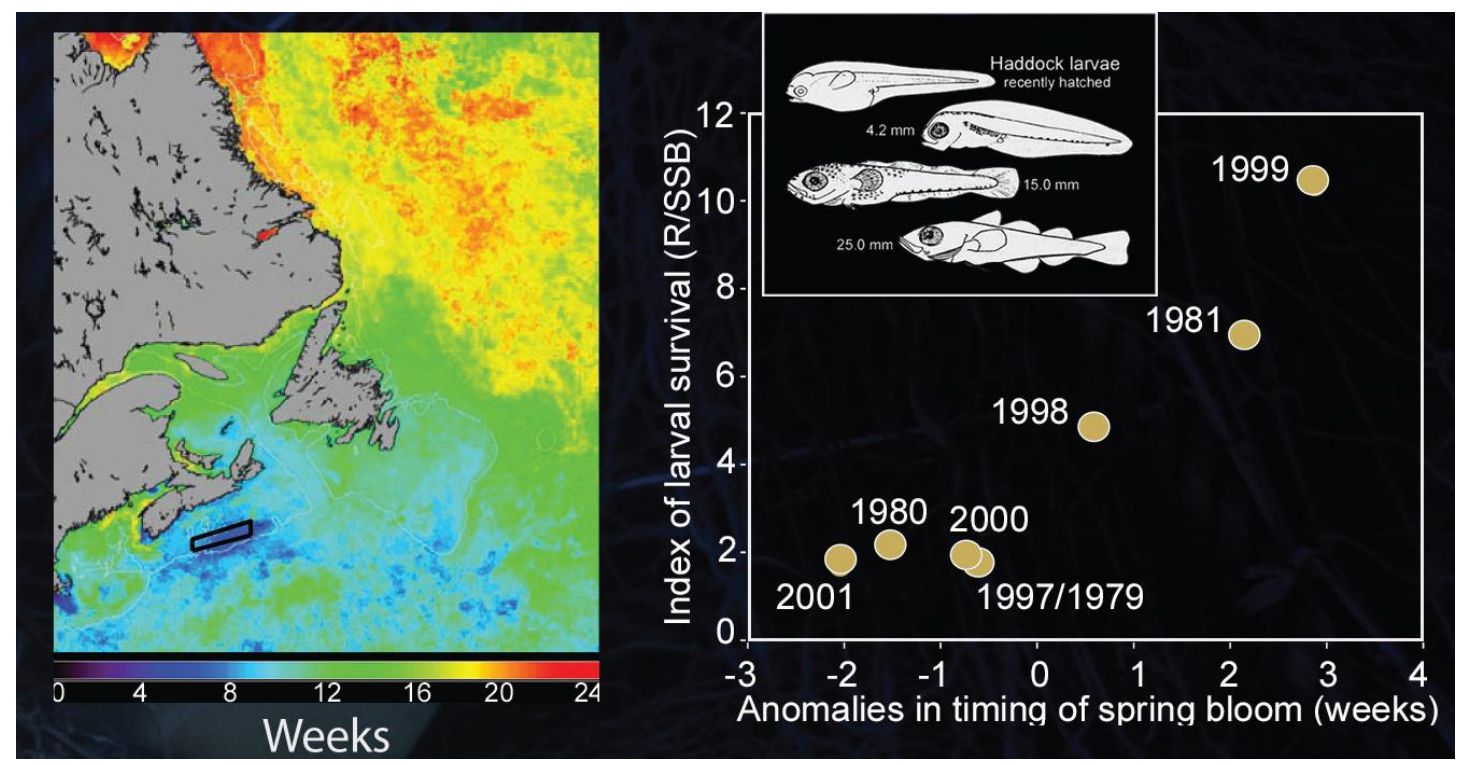

Figure 1: (left) Timing of the maximum phytoplankton biomass in the Northwest Atlantic from February to July, derived from SeaWiFS (Sea-viewing Wide Field of View Sensor) climatology (1998-2001). (right) Relationship between larval haddock survival index (normalized to recruitment) and the local anomalies in bloom timing. Data from the continental shelf off east and southern Nova Scotia (see black rectangle on map) for the periods 1979-1981 and 1997-2001. Adapted from Platt et al. (2003).

Earth observation data can also be used to monitor water quality as a tool in coastal-zone management, for example to study the degradation of coastal habitats through removal of mangroves or increased sediment load from river outflow. Furthermore, Earth observation data can be useful in monitoring the onset, expansion and fate of intense phytoplankton blooms or Harmful Algal Blooms (HABs). Water quality and eutrophication of coastal waters affect fish habitats by inducing, for example, anoxic conditions, and thus the monitoring of sensitive regions using Earth-observation data can be used as an aid to the fisheries and aquaculture industry. It also allows the visualisation and quantification of the effect on the marine ecosystem of major perturbations at regional levels, for example El Niño.

Finally, Earth-observation data can be used to help delineate optimal sites for marine protected areas and also habitats of species at risk. In addition, it can be used to monitor no-catch areas. For example, a Hawaiian study of the endangered Loggerhead turtle, in which turtles were tagged with GPS facilities and matched with their optimal biological and physical environment, has proven to be very useful in identifying their habitat index and in reducing turtle by-catch by limiting fisheries in these regions (Fig. 2).

\subsection{Remote Sensing Applications to Fish Harvesting}

Exploration of fishery resources using remote-sensing techniques is based on the development of methods for identification of feeding grounds where fish tend to accumulate. In general, physical forcing such as wind and temperature affect the mixing of the water column. When such events occur, the input of nutrients to the photic zone promotes the growth of phytoplankton. The increase in phytoplankton biomass, and the zooplankton community grazing on it, attracts pelagic fish to these areas. Similarly, the sinking of fecal pellets and senescent phytoplankton from regions of high biological activity will support the feeding of demersal fish as well. It has been established that fronts in thermal or chlorophyll gradients often indicate areas of high biological productivity. Moreover, from field and satellite data, optimal physical (temperature) and biological (chlorophyll) conditions have been established for some commercial fish, such as the skipjack tuna and the Japanese common squid, both species commercially fished in Japanese waters, which allow identification of areas with high catch probability. 


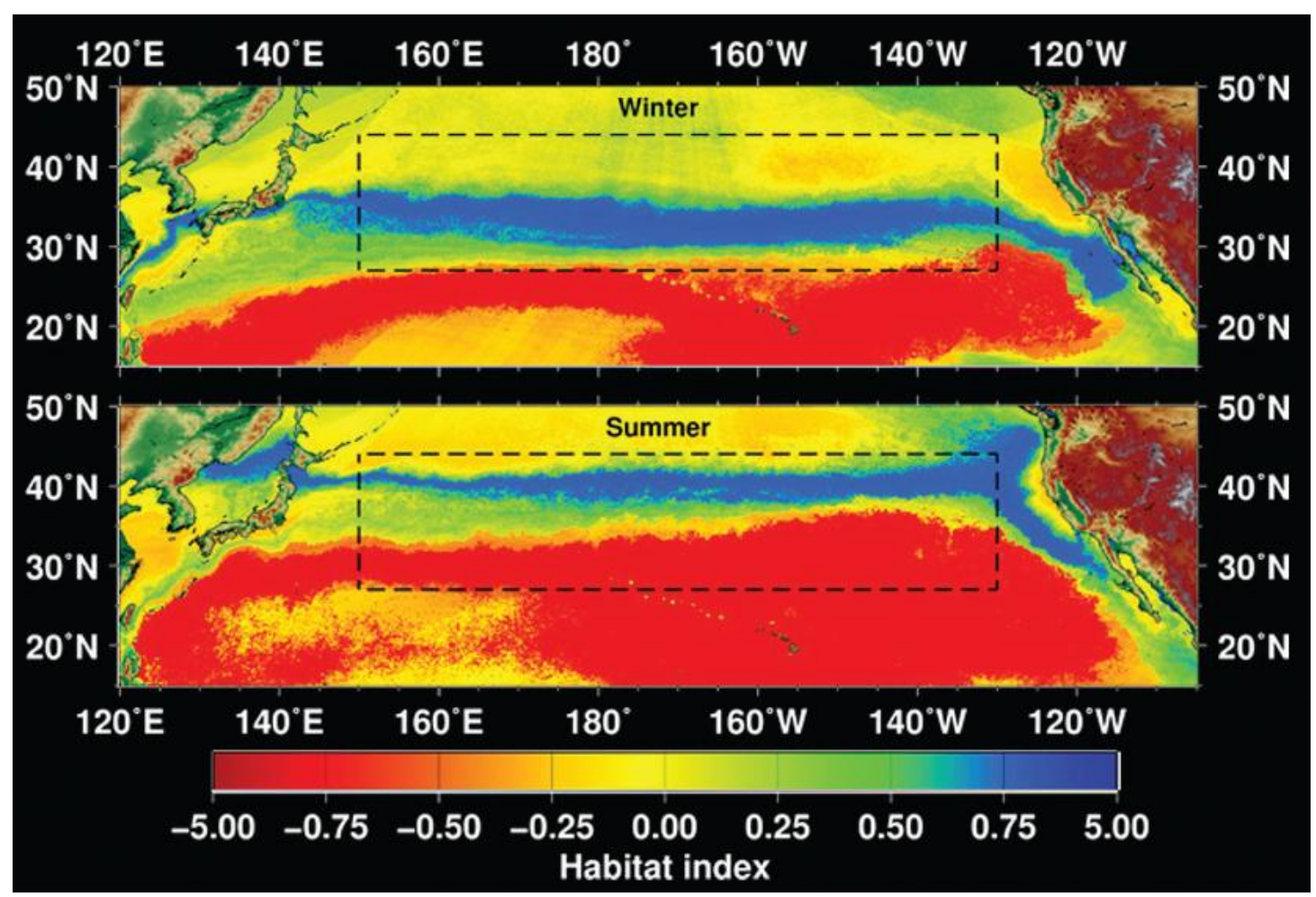

Figure 2: Location of Potential Fishing Zones (PFZ) off the coast of India estimated from remotely-sensed data (chlorophyll concentration from OCM (Ocean Colour Monitor), temperature from AVHRR (Advanced Very High Resolution Radiometer) and wind from QuikSCAT-SeaWinds). PFZs are indicated by the black circles. Satellite image provided by R.M. Dwivedi (SAC/ISRO (Space Applications Centre/Indian Space Research Organization), India), under the (Indian Remote Sensing Satellites) IRS-P4 OCM Utilization Programme and SATCORE (Satellite Coastal and Oceanographic Research).

Earth observation data can be used to identify Potential Fishing Zones (PFZ) or optimal agglomeration areas for specific fish species, allowing fishermen to work more effectively and economise on fuel (Fig. 3). This approach has been promoted in a few countries such as India, Japan and Spain (Canary Island), and have proven to be very successful in increasing the efficiency of fishing, with for example an increase in catch per unit effort by $70-100 \%$ in Indian waters, and a reduction in search time up to $70 \%$ depending on the fisheries. The goal is certainly not to encourage overfishing, but to provide practical ways for sustainable management and more economical harvesting.

\section{SAFARI ACTIVITIES}

To promote such applications of Earth observation data to fisheries, SAFARI was very active on a number of fronts, addressing all levels of participants in the global fisheries management, including decision makers and policy makers, research scientists, government officials and resource managers, and people from the fisheries industries. Examples of such activities are listed below.

\subsection{The ministerial-level activities}

The activities of SAFARI were promoted at the GEO Ministerial Summit held in Cape Town, South Africa, on November 27-29, 2007 within the Ocean United Exhibit. An article entitled: "Applications of remote sensing in fisheries and aquaculture" was published in the GEO book The Full Picture in 2007, and distributed to all Ministers attending the GEO Ministerial Summit. In addition, SAFARI was represented at Oceanology International held in London, England, on February 11-13, also as part of the Ocean-United booth.

\subsection{Scientific-activities}

The first SAFARI international workshop entitled "International Workshop on the Use of RemotelySensed Data as an Aid to Fisheries Research and Fisheries Management" was held at the Bedford Institute of Oceanography, Dartmouth, Canada in March 2008. An outcome of the workshop will be the publication of a monograph in the IOCCG Report Series, entitled "Remote Sensing in Fisheries and Aquaculture". The monograph will address a number of issues related to fisheries research and management 


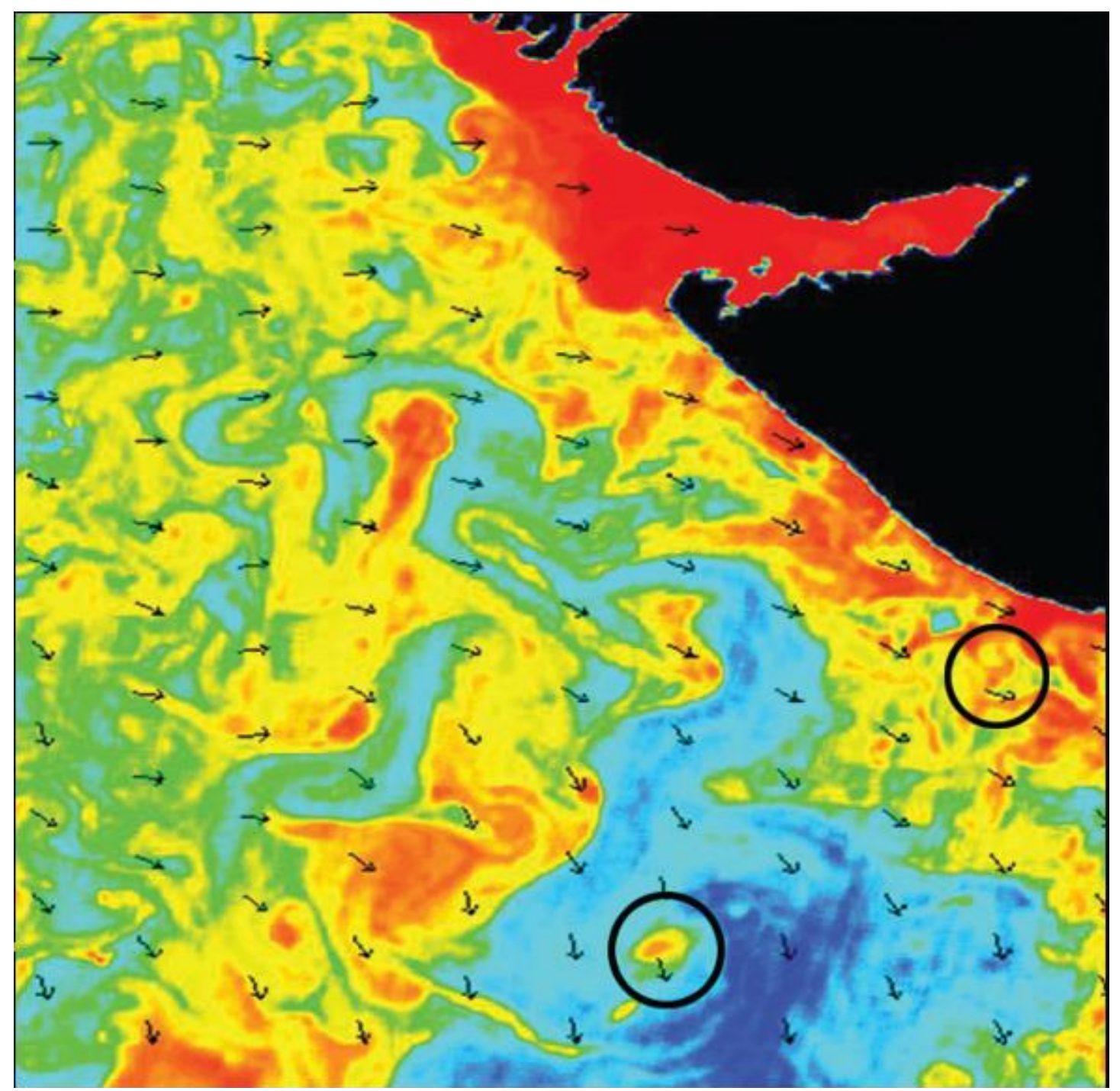

Figure 3: Climatological habitat map for pelagic loggerhead sea turtles in the North Pacific, based on a number of variables including satellite data (SST (Sea Surface Temperature) and SeaWiFS chlorophyll) for two different seasons. Blue areas represent a high probability of finding loggerhead sea turtles. Longline fisheries should be restricted from these areas to lower bycatch rates. Modified from Kobayashi et al. (2008).

including ecosystem variability and climate change, and it will also examine several remote sensing applications including stock assessment, fisheries management, fish harvesting and marine aquaculture. The monograph is the result of contributions from more than 50 researchers and will be available by late 2009.

SAFARI also organised an International workshop at the 2008 SPIE Asia-Pacific Remote Sensing Symposium, (November 17-21, 2008, New Caledonia) to address remote-sensing applications to fisheries adapted to the particular needs and problems of Western and Central Pacific Island countries. A 16page report of the workshop and its recommendations was published in the Proceedings of the SPIE AsiaPacific Remote Sensing meeting.

Finally, SAFARI is organizing a 3-day international symposium entitled "Remote Sensing and Fisheries" scheduled to take place in Kochi, India (15-17 February 2010). The symposium will be a special forum on regional and global applications of remote sensing to fisheries and aquaculture. 


\subsection{Outreach activities}

SAFARI organized an information and discussion session at the Bedford Institute of Oceanography, Canada (13 March 2009) to inform representatives from the government and the private commercial fishing sector about the various applications of remotely-sensed data in fisheries management. The information session was a great success and will be repeated in the future in other national and international venues.

\section{FUTURE CHALLENGES}

The SAFARI project has initiated interactions with the international ChloroGIN network (Chlorophyll Global Integrated Network), which is a global extension of the South American Antares network established by IOCCG (International Ocean-Colour Coordinating Group) and POGO (Partnership for Observation of the Global Oceans) to study long-term changes in coastal ecosystems around Latin America. The ChloroGIN network is being developed under the GEO Task EC09-01. Bringing together experts from SAFARI and ChloroGIN at the international level will help understand the ecosystem structure and functioning, and will ultimately allow the implementation of an ecosystem-based management for sustainable fisheries on an international scale in an operational mode through modeling efforts.

\subsection{Recommendations:}

Add global fisheries data (species, catch numbers, efforts, etc.) to the ChloroGIN portal, along with Earth observation data (chlorophyll-a, sea-surface temperature and other ocean colour product such as coloured dissolved organic matter, particulate carbon, suspended sediment and the diffuse attenuation coefficient), as a demonstration project. Feasibility has been proved by the Plymouth Marine Laboratory but example data sets are required to demonstrate the system.

Encourage Agencies to launch geostationary oceancolour satellites, such as the Korean GOCI sensor onboard COMS-1, to be launched in early 2010. Geostationary sensors allow the observation of a specific region at a high temporal resolution. This is particularly important for the monitoring of rapid physical and biological processes such as development of HABs.

Encourage development of ocean-colour sensors with increased spectral resolution, ideally moving toward hyperspectral resolution. This is essential for identification of phytoplankton functional types as well as improved quantification of chlorophyll and total suspended sediments, differentiation of dissolved organic compounds, monitoring of potentially toxic algal blooms in eutrophic coastal and inland waters, and the estimation of processes such as primary production in inland and coastal waters.

Future research in the area of fisheries management will rely heavily on Earth observation data, including ocean colour radiometry, thus it is essential to ensure the continuity of this data stream. This is currently being addressed by the IOCCG's Ocean Colour Radiometry Virtual Constellation (Community White Paper), which should be supported by all agencies.

High spatial resolution $(<300 \mathrm{~m})$ of all future oceancolour sensors should be promoted to help develop improved ocean-colour products in coastal waters.

\section{ACKNOWLEDGEMENTS}

The international coordination activities of SAFARI are funded by the Canadian Space Agency (CSA). SAFARI is the lead of GEO Task AG-06-02, and the SAFARI secretariat, established through CSA, is the main point of contact for the task. 